I7 ; and besides, the important observation of the disappearance of the comet at the sun's limb is very valuable. Now then, if it will be possible to secure some observations in the remaining days the comet will be visible, I am sure we shall have a large amount of material to study upon.

I may add that Mr. Common and I saw the comet a few days ago. With magnifying power of 120 and 150 we were not able to distinguish the division of the nucleus, but with a higher power we saw five bright points; one of these, corresponding to that seen before, remains the brightest. The comet has all the appearance of a little curve convex to the horizon, and is still a very bright object, as Mr. Common was able to see it pretty well with only six inches aperture and in moonlight.

I3, Pembridge Crescent, Bayswater, W.

E. RISTORI

\section{Aino Ethnology}

LET me basten to assure Herr Rein that nothing could have been further from my intention than to question the "love of truth," which is conspicuous in his work on Japan. I trust he will consider as absolutely withdrawn any expression of mine which he fancies might at all bear such a construction. $\mathrm{His}$ authorities I did not quote, because I attached much more importance to the weight of his name than to theirs. The almost unanimous opinion of original observers is opposed to their conclusions, which I was certainly somewhat surprised to find adopted by Herr Rein. But as he has not himself visited the Aino people, the question of their affinities need not be further argued here. I may state, however, that to Steube and von Siebold must now be added Herr Kreitner, of the Szechenyi expedition, who emphatically removes them from the Mongolic, and "assimilates them to the Caucasic type" ("Im Fernen Osten," Vienna, I881, p. 318).

A. H. Keane

\section{Auroral Experiments in Finland}

IN the note in NATURE, vol. xxvii. p. 322, in which you refer to my telegrams from Sodankylä, there is a misunderstanding concerning the apparatus which I made use of in the experiments. This apparatus, which I call in Swedish "Utfrömningo-apparat" (streaming apparatus), was constructed of uncovered copper wire, provided at each half-metre with fine erected points. That wire was led in slings to the top of the hill, and reposed on the usual telegraph insulators. From one end of this wire was conducted a covered copper wire on insulators to the foot of the hill ( 600 feet high), and there joined a plate of zinc interred in the earth. In this circuit was put a galvanometer.

It was this apparatus which produced both the yellow-white halo at Oratunturi and the straight beam of aurora borealis at Pietarintunturi, as the positive current in the galvanometer at both places. The terrestrial current diminishes (or ceases) below the belt of maxima of the aurora borealis. S. LEMSTRöM

Helsingfors

\section{Flamingoes and Cariamas}

In NATURE, vol. xxvii. p. 334, an accotnt is given of the curious behaviour of a flamingo towards a cariama. May I point out that this habit of the flamingo was observed in 1869 by Mr. Bartlett, and will be found in a P.S. to a paper of his entitled "Remarks upon the Habits of the Hornbills," read before the Zoological Society, February 25, 1869. The liquid was examined by Dr. Murie, and is said to have consisted almost entirely of blood. A short notice of the habit, communicated by Mr. Bartlett, appears also in Buckland's Edition of "White's Selborne."

Cambridge, February 19

\section{THE APPROACHING FISHERY EXHIBITION}

$\mathrm{F}$ ROM the cheerful note of preparation which is now being sounded, we presume the opening of the International Fisheries Exhibition will take place punctually on the day which has been fixed for that eventMay I. That the Exhibition will be successful, both in a pecuniary sense and as an exposition of fishery economy and of the natural history of our food fishes, may, we think, be even now predicted. The two exhibitions by which it has been preceded, those of Edinburgh and Norwich, not only paid all expenses, but left a handsome surplus; so that, with the vast population of London and the strangers who daily come within its gates to work upon, the promoters of the exposition are warranted in believing that it will prove a success. It will undoubtedly be the greatest affair of the sort which has yet been designed, and will occupy a site twice as large as the Norwich and Edinburgh exhibitions joined together. The fishery exhibition which was held at Berlin three years ago was visited by nearly half a million persons, but it was only open for ten weeks, whilst the show to be held at South Kensington will remain open for six months, and as the population of London is more than four times greater than that of Berlin, we may calculate on the visitors to the Fishery Exhibition running into big figures; - two million persons at a shilling each would represent a sum of one hundred thousand pounds. Already a large guarantee fund has been subscribed by corporations and private persons, and there is no reason why Parliament should not be asked for a grant in aid, although any money that might be granted may not be required. It is right to say that as a nation we play a rather "mean" part in such matters, and are quite outdone in liberality by other countries. America, for instance, is sending us an "exhibit" which will cost that country ten thousand pounds, and other foreign countries are acting in an equally liberal spirit. If we were asked on any occasion to reciprocate, what answer could we make? We have positively nothing that we could send. With the exception of the toy museum left to the country by Mr. Frank Buckland, we possess nothing in the shape of a national collection illustrative of fishery economy; hence the Exhibition which is about to open assumes very much the shape of a commercial enterprise, and becomes a gate-money show. But that is better than nothing, and it is to be hoped that from the debris of the approaching exposition a substantial addition may be made to the Buckland Museum of economic fish culture, and if we may be permitted to make such a suggestion, the aquarium should, if that is possible, be so arranged that it could be left as a permanent attraction for all who are interested in the natural history of fish and in the proper ingathering of the harvest of the sea.

Great expectations are entertained as to the value of the lessons to be taught at the approaching Exhibition. We are undoubtedly in need of knowledge of all kinds regarding the natural history of our fishes. From the whitebait to the whale we are singularly deficient in those details of fish life that would prove valuable to persons engaged in fishery enterprise. In the matter of well-planned investigation into the natural history of the British food fishes we are far behind America, where information of the most valuable kind is systematically collected and disseminated. As a matter of fact, we have (as a nation) done almost nothing in respect of adding to the knowledge of the public. Some individuals have been toying with the subject of Pisciculture, whilst in the seas that pertain to the United States fish-breeding on an extended scale has been long in operation under the auspices of the Government. It will not be the fault of the promoters of the approaching Exhibition if attention is not aroused to our want of interest (as a people) in the sea-fisheries of the country. We have therefore every reason to be grateful to those who have stepped to the front in order to promote this enterprise; the men who have assumed the lead have nothing to gain personally by its success - they are working in the interests of the public, knowing well that the fisheries of the surrounding coasts contribute largely to the commissariat of the country.

A portly prospectus, so far as its contents are concerned, has been issued, indicative of what will be shown in the Exposition, and from that document we gather that a large 